\title{
SHORT- AND LONG-RUN PLANT CAPACITY NOTIONS: DEFINITIONS AND COMPARISON*
}

\author{
Giovanni Cesaroni ${ }^{\dagger}$ \\ Kristiaan Kerstens ${ }^{*}$ \\ Ignace Van de Woestyne ${ }^{\S}$
}

\begin{abstract}
Starting from the existing input- and output-oriented plant capacity measures, this contribution proposes new long-run input- and output-oriented plant capacity measures. While the former leave fixed inputs unchanged, the latter allow for changes in all input dimensions to gauge either a maximal plant capacity output or a minimal input combination at which non-zero production starts. We also establish a formal relation between the existing short-run and the new long-run plant capacity measures. Furthermore, for a standard nonparametric frontier technology, all linear programs as well as their variations are specified to compute all efficiency measures defining these short- and long-run plant capacity concepts. Furthermore, it is shown how the new long run plant capacity measures are identical to existing models of a variable returns to scale technology without inputs or without outputs: thus, we offer an interesting production economic justification for these models. Finally, we numerically illustrate this basic relationship between these short-run and long-run technical concepts of capacity utilisation and provide an empirical application.
\end{abstract}

Keywords: Data Envelopment Analysis; efficiency; plant capacity utilisation.

$\dagger$ Department for local development, Prime Minister's Office, Via della Mercede 9, IT00187 Rome, Italy.

‡ CNRS-LEM (UMR 9221), IESEG School of Management, 3 rue de la Digue, FR-59000 Lille, France. Tel: ++ 33(0)320545892, Fax: ++ 33(0)320574855, k.kerstens@ieseg.fr. Corresponding author.

$\S \quad$ KU Leuven, Research unit MEES, Warmoesberg 26, BE-1000 Brussel, Belgium.

June 2017

Revision: February 2018

Second Revision: June 2018

* We thank three referees for their detailed comments that have led to a substantial improvement of this contribution. We remain responsible for any remaining errors. 


\section{INTRODUCTION}

The notion of plant capacity was introduced by Johansen (1968, p. 362) as “... the maximum amount that can be produced per unit of time with existing plant and equipment, provided that the availability of variable factors of production is not restricted." Färe (1984) established necessary and sufficient conditions for the existence of plant capacity. For instance, he shows that the plant capacity notion cannot be obtained for certain popular parametric technology specifications. Färe, Grosskopf and Kokkelenberg (1989) and Färe, Grosskopf and Valdmanis (1989) introduce a nonparametric frontier framework in which plant capacity as well as a measure of the capacity utilisation can be determined from data on observed inputs and outputs using a pair of outputoriented efficiency measures.

For over 25 years, no major methodological innovation has occurred related to this plant capacity concept. While input- and output-oriented efficiency measurement models have become widely available in most frontier models (e.g., Hackman (2008) or Zhu (2014)), only an outputoriented plant capacity concept was existent. Recently, Cesaroni, Kerstens and Van de Woestyne (2017) use the same framework to define a new input-oriented measure of plant capacity utilisation based on a couple of input-oriented efficiency measures.

In addition to this engineering notion of plant capacity, one can mention at least three ways of defining an economic, cost-based capacity concept in the literature (e.g., Nelson (1989)). A first concept concentrates on the outputs produced at short-run minimum average total cost given existing input prices (e.g., Hickman (1964)). A second definition focuses on the outputs for which short- and long-run average total costs curves are tangent (e.g., Segerson and Squires (1990)). A third capacity notion considers the outputs determined by the minimum of the long-run average total costs (e.g., Klein (1960)). Alternative economic capacity concepts are discussed in GrifellTatjé and Lovell (2014). 
Each of these capacity notions has its advantages and disadvantages. ${ }^{1}$ Estimates of plant capacity have regularly been reported in the literature, though it cannot be denied that the plant capacity notion is nowhere as popular as some of the cost-based notions of capacity.

Both plant capacity concepts as well as each of these cost-based notions attempt to determine the short run inadequate or excessive utilisation of existing fixed inputs. One exception is the minimum of the long-run average total cost function: it assumes that all inputs are variable. Therefore, by analogy there is in our view a need to define new long-run plant capacity concepts that are similar in nature to the latter concept and that take a long-run perspective wherein all inputs are variable.

This paper thus develops two new plant capacity measures using nonparametric frontier technologies that take a long run instead of a short run perspective: one output-oriented, and one input-oriented. Furthermore, this paper compares both these short- and long-run plant capacity notions to one another. It turns out to be the case that the long run plant capacity measures are identical to existing models of a variable returns to scale technology without inputs or without outputs as proposed by Lovell and Pastor (1999). Therefore, these new long run plant capacity measures offer an interesting production economic justification for the use of these existing models of Lovell and Pastor (1999).

The paper is structured as follows. Section 2 introduces technologies and their representations using efficiency measures, the inverses of distance functions. Section 3 defines the traditional short-run input- and output-oriented plant capacity measure. Then, the new long-run plant capacity measures are proposed. Also a relation between short- and long-run plant capacity measures is established. For a standard nonparametric frontier technology, Section 4 specifies all linear programs as well as their variations needed to compute all efficiency measures defining these short- and long-run plant capacity concepts. It also establishes a relation with the literature on frontier

\footnotetext{
1 A brief summary of how these different engineering and economic capacity concepts can be transposed in a nonparametric frontier framework is found in De Borger et al. (2012) and Grifell-Tatjé and Lovell (2014).
} 
models without inputs and without outputs. A numerical example in Section 5 illustrates these relations between short-run and long-run plant capacity concepts. Some concluding remarks are made in the final section.

\section{TECHNOLOGY: DISTANCE FUNCTIONS AND EFFICIENCY MEASURES}

We start by defining technology and some basic notation. Given an $N$-dimensional input vector $\left(x \in \square_{+}^{N}\right)$ and an $M$-dimensional output vector $\left(y \in \square_{+}^{M}\right.$ ), the production possibility set or technology can be defined: $S=\{(x, y): x$ can at least produce $y\}$. It is customary to impose the following conditions on the input and output data (Färe, Grosskopf and Lovell (1994: p. 44-45)): (i) each producer uses nonnegative amounts of each input to produce nonnegative amounts of each output; (ii) there is an aggregate production of positive amounts of every output, and an aggregate utilisation of positive amounts of every input; and (iii) each producer employs a positive amount of at least one input to produce a positive amount of at least one output. Associated with this technology $S$, the input set denotes all input vectors $x \in \square_{+}^{N}$ that can produce at least a given output

vector $y \in \square_{+}^{M}: L(y)=\{x:(x, y) \in S\}$. Analogously, the output set associated with $S$ denotes all output vectors $y \in \square_{+}^{M}$ that can be produced from at most a given input vector $x \in \square_{+}^{N}: P(x)=$ $\{\mathrm{y}:(x, y) \in S\}$. Furthermore, the output set $P=\{y: \exists x:(x, y) \in S\}$ denotes the set of all possible outputs regardless of the needed inputs.

In this contribution, technology $S$ satisfies some combination of the following standard assumptions: (S.1) Possibility of inaction and no free lunch; (S.2) Technology $S$ is closed; (S.3) Strong input and output disposability; (S.4) Technology $S$ is convex (see, e.g., Färe, Grosskopf and Lovell (1994) or Hackman (2008) for details). Note that not all of these axioms are simultaneously 
maintained in the empirical analysis. ${ }^{2}$ Note furthermore that we do not add a specific returns to scale assumption: this amounts to a flexible or variable returns to scale hypothesis.

It is common to partition the input vector into a fixed and variable part $\left(x=\left(x^{f}, x^{v}\right)\right)$, with $x^{v} \in \square_{+}^{N_{v}}$ and $x^{f} \in \square_{+}^{N_{f}}$ with $N=N_{v}+N_{f}$. This leads to sharpen the conditions on the input and output data. Färe, Grosskopf and Kokkelenberg (1989: p. 659-660) state: each fixed input is used by some producer and each producer uses some fixed input. We also need: each variable input is used by some producer and each producer uses some variable input. Inspired by Färe, Grosskopf and Valdmanis (1989: p. 127), we define a short run technology $S^{f}=\left\{\left(x^{f}, y\right)\right.$ : there exists some $x^{v}$ such that $\left(x^{f}, x^{v}\right)$ can produce at least $\left.y\right\}$ and the corresponding input set $L^{f}(y)=\left\{x^{f}:\left(x^{f}, y\right) \in S^{f}\right\}$ and output set $P^{f}\left(x^{f}\right)=\left\{y:\left(x^{f}, y\right) \in S^{f}\right\}$.

Note that this short run technology $S^{f}$ is obtained by projection of the initial technology $S \in \square^{N+M}$ into the subspace $\square^{N_{f}+M}$ (i.e., by setting all variable inputs equal to zero). ${ }^{3}$ By analogy, the set $P$ is realized by projection of technology $S \in \square^{N+M}$ into $\square^{M}$ (i.e., by setting all inputs equal to zero). ${ }^{4}$ We return to the precise relations between the set $S$ and its projections $S^{f}$ and $P$ when developing the numerical illustration in Section 5.

One can define the radial input efficiency measure as:

$$
D F_{i}(x, y)=\min \{\lambda: \lambda \geq 0, \lambda x \in L(y)\}
$$

It offers a complete characterisation of the input set $L(y)$. The main properties are that it is situated between zero and unity $\left(0<D F_{i}(x, y) \leq 1\right)$, with efficient production on the boundary (isoquant) of

\footnotetext{
${ }^{2}$ E.g., the nonparametric convex strongly disposable technology with variable returns to scale does not satisfy inaction: see also infra.

${ }^{3}$ This projection maps $\left(x^{f}, x^{v}, y\right)$ onto $\left(x^{f}, 0, y\right)$ which can mathematically be identified with $\left(x^{f}, y\right)$. More information on this projection is provided in Section 4.1 .

${ }^{4}$ This projection maps $\left(x^{f}, x^{v}, y\right)$ onto $(0,0, y)$ which can mathematically be identified with $y$. More information on this projection is provided in Section 4.2 .
} 
the input set $L(y)$ represented by unity, and that the radial input efficiency measure has a cost interpretation (see, e.g., Hackman (2008)).

By analogy, denote the radial input efficiency measure of the input set $L^{f}(y)$ by $D F_{i}^{f}\left(x^{f}, y\right)$. This is defined as follows: $D F_{i}^{f}\left(x^{f}, y\right)=\min \left\{\lambda: \lambda \geq 0, \lambda x \in L^{f}(y)\right\}$.

Next, one can define the radial output efficiency measure as:

$$
D F_{o}(x, y)=\max \{\theta: \theta \geq 0, \theta y \in P(x)\} .
$$

It offers a complete characterization of the output set $P(x)$. Its main properties are that it is larger than or equal to unity $\left(D F_{o}(x, y) \geq 1\right)$, with efficient production on the boundary (isoquant) of the output set $P(x)$ represented by unity, and that the radial output efficiency measure has a revenue interpretation (e.g., Hackman (2008)).

By analogy, denote the radial output efficiency measure of the output set $P^{f}\left(x^{f}\right)$ by $D F_{o}^{f}\left(x^{f}, y\right)$. Then, this efficiency measure can be defined as $D F_{o}^{f}\left(x^{f}, y\right)=\max \left\{\theta: \theta \geq 0, \theta y \in P^{f}\left(x^{f}\right)\right\}$. Next, denote $D F_{o}(y)=\max \{\theta: \theta \geq 0, \theta y \in P\}$. Contrary to the radial output efficiency measure (2), this new efficiency measure $D F_{o}(y)$ does not depend on a particular input vector $x$. Hence, this measure is allowed to choose the inputs needed for maximizing $\theta$.

Furthermore, we need the following particular definitions. First, $L(0)=\{x:(x, 0) \in S\}$ is the input set with zero output level. ${ }^{5}$ Second, $D F_{i}^{S R}\left(x^{f}, x^{v}, y\right)=\min \left\{\lambda: \lambda \geq 0,\left(x^{f}, \lambda x^{v}\right) \in L(y)\right\}$ is a sub-vector input efficiency measure reducing only the variable inputs. Third, $D F_{i}^{S R}\left(x^{f}, x^{v}, 0\right)=\min \left\{\lambda: \lambda \geq 0,\left(x^{f}, \lambda x^{v}\right) \in L(0)\right\}$ is the sub-vector input efficiency measure reducing variable inputs evaluated relative to this input set with a zero output level.

\footnotetext{
${ }^{5} L(0)$ can be equivalently defined by $L\left(y_{\min }\right)=\left\{x:\left(x, y_{\min }\right) \in S\right\}$ where $y_{\min }=\min _{k=1, \ldots, K} y_{k}$ whereby the minimum is taken in a component-wise manner for every output $y$ over all observations $K$.
} 


\section{PLANT CAPACITY UTILISATION: LITERATURE REVIEW AND DEFINITIONS}

Since this paper focuses on plant capacity, we discuss some empirical studies based on this concept. Since the large majority of empirical plant capacity studies focuses on fisheries and health care, we briefly summarise some of these studies.

The existing plant capacity measures can in fact be interpreted as focusing on the short run, where a subvector of fixed inputs cannot be changed. The new plant capacity measures take a long run perspective and assume that all inputs can be varied when determining plant capacity measures. We first treat the existing short-run plant capacity measures. Thereafter, the new long-run plant capacity measures are defined.

\subsection{Plant Capacity Utilisation: A Literature Review}

Felthoven (2002) analyses the impact of the American Fisheries Act (AFA) of 1998 on the Pollock fishery and finds that decommissioned vessels exhibited a lower level of technical efficiency and that the capacity utilization of the AFA-eligible vessels increased after the law came into effect. Other fisheries studies include Guyader and Daurès (2005) analysing the French seaweed fleet, Kirkley et al. (2003) focusing on the Malaysian purse seine fishery, Reid et al. (2003) reporting on the Western and Central Pacific Ocean tuna fishery, and Walden and Tomberlin (2010) discussing US bottom trawl gear fishing.

Valdmanis, Bernet and Moises (2010) compute state-wide hospital capacity in Florida based on the whole hospital population as part of an emergency preparedness plan. Starting from a scenario involving patient evacuations from Miami due to a major hurricane event, they assess whether hospitals in proximity to the affected market can absorb the excess patient flow. Alternative health care studies are Magnussen and Rivers Mobley (1999) comparing Norwegian and Californian hospitals, Karagiannis (2015) analysing Greek public hospitals, Kerr et al. (1999) focusing on Northern Irish acute hospitals, and Valdmanis, DeNicola and Bernet (2015) reporting on Florida's public health departments. 
Apart from the use of basic plant capacity estimates, one can also mention some methodological refinements making use of the plant capacity concept. These plant capacity estimates are also parameters in a so-called short-run industry model trying to reallocate outputs and resources across units in an effort to reduce excess capacity at the industry level. For instance, Yagi and Managi (2011) explore such model in a fishery context. Another methodological refinement using the plant capacity notion is its inclusion in a decomposition of the Malmquist productivity index (see De Borger and Kerstens (2000) and the extension by Yu (2007)). Färe, Grosskopf and Kirkley (2000) suggest integrating the plant capacity notion into the revenue function and the cost indirect output distance function and they derive a decomposition of the corresponding Malmquist productivity indices.

\subsection{Short-Run Plant Capacity Utilisation}

We now first recall the definition of the short-run output-oriented plant capacity utilisation measure (see Färe, Grosskopf and Kokkelenberg (1989) and Färe, Grosskopf and Valdmanis (1989)). The definition of the output-oriented measure of plant capacity utilisation $\left(P C U_{o}^{S R}\left(x, x^{f}, y\right)\right)$ requires solving an output efficiency measure relative to both a standard technology and the same technology without restrictions on the availability of variable inputs and is defined as:

$$
P C U_{o}^{S R}\left(x, x^{f}, y\right)=\frac{D F_{o}(x, y)}{D F_{o}^{f}\left(x^{f}, y\right)}
$$

where $D F_{o}(x, y)$ and $D F_{o}^{f}\left(x^{f}, y\right)$ are output efficiency measures relative to technologies including respectively excluding the variable inputs as defined before. Notice that $0<P C U_{o}^{S R}\left(x, x^{f}, y\right) \leq 1$, since $1 \leq D F_{o}(x, y) \leq D F_{o}^{f}\left(x^{f}, y\right)$. Thus, output-oriented plant capacity utilisation has an upper limit of unity, but no lower limit. This output-oriented plant capacity utilisation compares the maximum amount of outputs with given inputs to the maximum amount of outputs in the sample with 
potentially unlimited amounts of variable inputs, whence it is smaller than unity. It answers the question how the current amount of efficient outputs relates to the maximal possible amounts of efficient outputs. Notice that the last efficiency measure provides a reliable estimate of the maximum amount of outputs to the extent that the sample also contains the largest plants combining the highest levels of variable inputs with the highest levels of outputs.

Following Färe, Grosskopf and Kokkelenberg (1989: 660), this leads to the following shortrun output-oriented decomposition:

$$
D F_{o}(x, y)=D F_{o}^{f}\left(x^{f}, y\right) \cdot P C U_{o}^{S R}\left(x, x^{f}, y\right) .
$$

Thus, the traditional output-oriented efficiency measure $D F_{o}(x, y)$ can be decomposed into a biased plant capacity measure $D F_{o}^{f}\left(x^{f}, y\right)$ and an unbiased plant capacity measure $P C U_{o}^{S R}\left(x, x^{f}, y\right)$ depending on whether the measure ignores inefficiency or adjusts for inefficiency (following the terminology introduced by Färe, Grosskopf and Kokkelenberg (1989: 661)).

Cesaroni, Kerstens and Van de Woestyne (2017) offer a definition of the input-oriented plant capacity measure $\left(P C U_{i}\left(x, x^{f}, y\right)\right)$ :

$$
P C U_{i}^{S R}\left(x, x^{f}, y\right)=\frac{D F_{i}^{S R}\left(x^{f}, x^{v}, y\right)}{D F_{i}^{S R}\left(x^{f}, x^{v}, 0\right)},
$$

where $D F_{i}^{S R}\left(x^{f}, x^{v}, y\right)$ and $D F_{i}^{S R}\left(x^{f}, x^{v}, 0\right)$ are both sub-vector input efficiency measures reducing only the variable inputs relative to the technology, whereby the latter efficiency measure is evaluated at a zero output level. ${ }^{6}$ Notice that $\operatorname{PCU}_{i}^{S R}\left(x, x^{f}, y\right) \geq 1$, since $0<D F_{i}^{S R}\left(x^{f}, x^{v}, 0\right) \leq$ $D F_{i}^{S R}\left(x^{f}, x^{v}, y\right) \leq 1$. Thus, input-oriented plant capacity utilisation has a lower limit of unity, but no upper limit. This input-oriented plant capacity utilisation compares the minimum amount of variable inputs for given amounts of outputs with the minimum amount of variable inputs with output levels where production is initiated, whence it is larger than unity. It answers the question

\footnotetext{
6 An important issue raised by a referee is the dual relation of the efficiency measure $D F_{i}^{S R}\left(x^{f}, x^{v}, 0\right)$ with the cost function. We conjecture that this efficiency measure is somehow related to the setup cost, i.e., the cost of starting to produce positive amounts of outputs. The exact duality relationship remains to be explored in future work.
} 
how the amount of variable inputs compatible with the initialisation of production must be scaled up to produce the current amount of outputs. Notice that the first efficiency measure provides a reliable estimate of the minimum amount of variable inputs compatible with the start-up of production to the extent that the sample also contains the smallest plants combining the lowest levels of variable inputs with zero or low levels of outputs. ${ }^{7}$

This leads to the following short-run input-oriented decomposition:

$$
D F_{i}^{S R}\left(x^{f}, x^{v}, y\right)=D F_{i}^{S R}\left(x^{f}, x^{v}, 0\right) \cdot P C U_{i}^{S R}\left(x, x^{f}, y\right) .
$$

Thus, the traditional sub-vector input-oriented efficiency measure $D F_{i}^{S R}\left(x^{f}, x^{v}, y\right)$ is decomposed into a biased plant capacity measure $D F_{i}^{S R}\left(x^{f}, x^{v}, 0\right)$ and an unbiased plant capacity measure $P C U_{i}^{S R}\left(x, x^{f}, y\right)$.

\subsection{Long-Run Plant Capacity Utilisation}

A new definition of a long-run output-oriented measure of plant capacity utilisation $\left(P C U_{o}^{L R}(x, y)\right)$ involves an output efficiency measure relative to both a standard technology and the same technology without restrictions on the availability of inputs and is defined as:

$$
P C U_{o}^{L R}(x, y)=\frac{D F_{o}(x, y)}{D F_{o}(y)}
$$

where $D F_{o}(x, y)$ and $D F_{o}(y)$ are output efficiency measures relative to technologies including all inputs respectively ignoring all inputs. Notice that $0<P C U_{o}^{L R}(x, y) \leq 1$, since $1 \leq D F_{o}(x, y) \leq$ $D F_{o}(y)$. Thus, long-run output-oriented plant capacity utilisation has an upper limit of unity, but no lower limit. This long-run output-oriented plant capacity utilisation compares the maximum amount of outputs with given inputs to the maximum amount of outputs in the sample with potentially

7 The zero output levels in fact allow for any output levels where production is initiated. It is easy to see that if one fixes for each output dimension the level at the minimum observed over all units (see $y_{\min }$ defined supra), then exactly the same solution for the sub-vector input efficiency measure $D F_{i}^{S R}\left(x^{f}, x^{v}, 0\right)$ would result. Thus, $D F_{i}^{S R}\left(x^{f}, x^{v}, 0\right)=D F_{i}^{S R}\left(x^{f}, x^{v}, y_{\min }\right)$. 
unlimited amounts of both fixed and variable inputs, whence it is smaller than unity. Since fixed inputs can now be adjusted, this implies that to mimic the maximum amount of outputs in the sample one may need investments to adjust production capacity (which is not the case in the shortrun version). The same remark applies as for the short-run version.

This leads to the following long-run output-oriented decomposition:

$$
D F_{o}(x, y)=D F_{o}(y) \cdot P C U_{o}^{L R}(x, y) .
$$

Thus, the traditional output-oriented efficiency measure $D F_{o}(x, y)$ can be decomposed into a biased plant capacity measure $D F_{o}(y)$ and an unbiased plant capacity measure $P C U_{o}^{L R}(x, y)$,

A new definition of the long-run input-oriented plant capacity measure $\left(P C U_{i}^{L R}(x, y)\right)$ is:

$$
P C U_{i}^{L R}(x, y)=\frac{D F_{i}(x, y)}{D F_{i}(x, 0)}
$$

where $D F_{i}(x, y)$ and $D F_{i}(x, 0)$ are both input efficiency measures aimed at reducing all input dimensions relative to the technology, whereby the latter efficiency measure is evaluated at a zero output level. ${ }^{8}$ This definition presupposes the following definition of an input efficiency measure reducing all inputs relative to an input set with a zero output level: $D F_{i}(x, 0)=\min \{\lambda: \lambda \geq 0, \lambda x \in L(0)\}$. Notice that $P C U_{i}^{L R}(x, y) \geq 1$, since $0<D F_{i}(x, 0) \leq$ $D F_{i}(x, y) \leq 1$. Thus, long-run input-oriented plant capacity utilisation has a lower limit of unity, but no upper limit. This long-run input-oriented plant capacity utilisation compares the minimum amount of all inputs for given amounts of outputs with the minimum amount of all inputs with outputs where production is initiated, whence it is larger than unity. It answers the question how the

\footnotetext{
8 A referee raises the issue about the dual relation of the efficiency measure $D F_{i}(x, 0)$ with the cost function. We conjecture again that this efficiency measure is somehow related to the setup cost, i.e., the cost of starting to produce positive amounts of outputs. Future work will have to explore the exact duality relationship.
} 
amount of all inputs compatible with the initialisation of production must be scaled up to produce the current amount of outputs. Again, the same remark applies as for the short-run version. ${ }^{9}$

This leads to the long-run input-oriented decomposition:

$$
D F_{i}(x, y)=D F_{i}(x, 0) \cdot P C U_{i}^{L R}(x, y) .
$$

Thus, the input-oriented efficiency measure $D F_{i}(x, y)$ is decomposed into a biased plant capacity measure $D F_{i}(x, 0)$ and an unbiased plant capacity measure $P C U_{i}^{L R}(x, y)$.

\subsection{Relations between Short- and Long-Run Plant Capacity Utilisation}

Figure 1 develops the geometric intuition behind the short-run and long-run plant capacity measures. The isoquant denoting the combinations of fixed and variable inputs yielding a given output level $L(y)$ is represented by the polyline $a b c d$ and its vertical and horizontal extensions at $a$ and $d$ respectively. We focus on observation $e$ to illustrate first the short-run output-oriented plant capacity utilisation measure: for a given fixed input vector, it scales up the use of variable inputs to reach a translated point $e^{\prime}$ that allows maximizing the vector of outputs. For the development of the short-run input-oriented plant capacity measure, it therefore seems logical to look for a reduction in variable inputs for given fixed inputs towards the translated point $e^{\prime \prime}$ that is situated outside the isoquant $L(y)$ because it produces an output vector of zero (it is compatible with the isoquant $L(0)$ that is situated lower).

\footnotetext{
9 Again, the zero output levels allow in fact for any output levels where production is started. If one fixes for each output dimension the level at the minimum observed over all units (see $y_{\min }$ defined supra), then the same solution for the input efficiency measure $D F_{i}(x, 0)$ would result. Thus, $D F_{i}(x, 0)=D F_{i}\left(x, y_{\min }\right)$.
} 


\section{Figure 1: Isoquant with Input and Output-oriented Plant Capacity Measures}

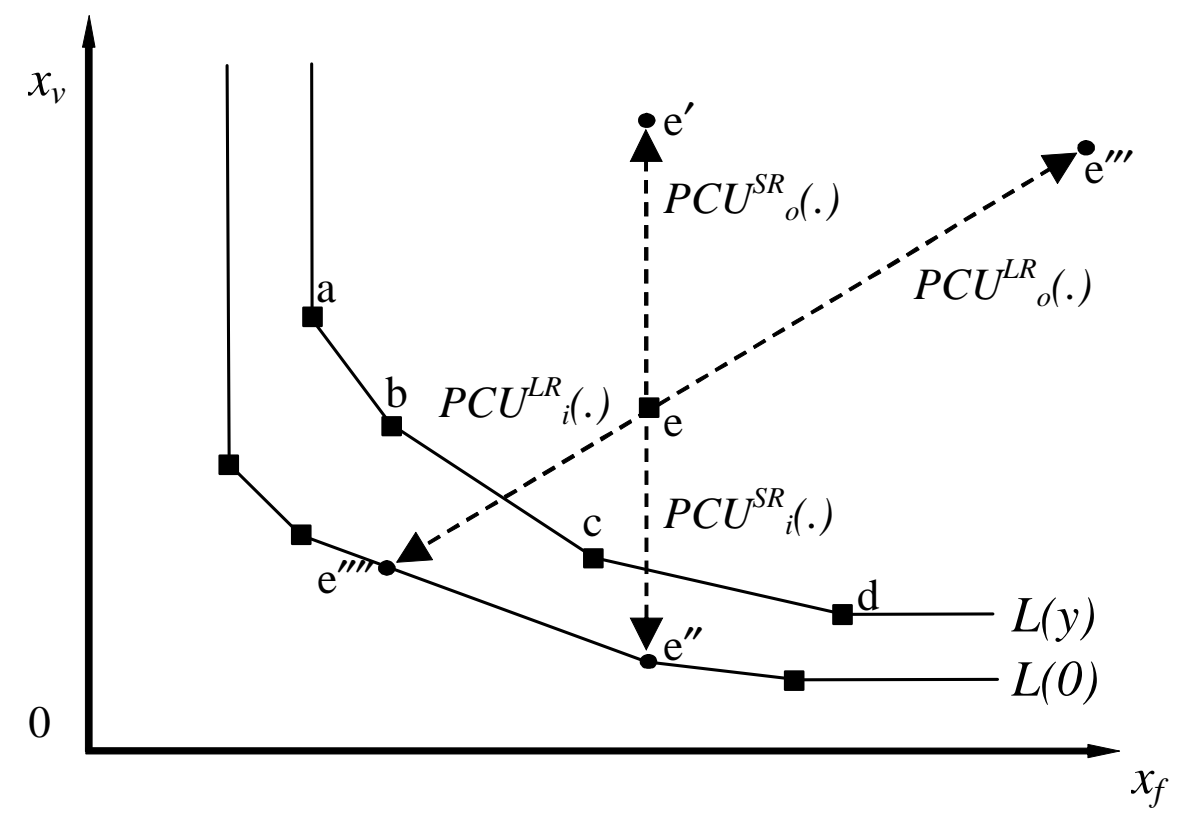

In brief, while the short-run output-oriented plant capacity measure evaluates capacity by contrasting the frontier outputs for a given observation with respect to the maximal outputs available net of inefficiency, the short-run input-oriented plant capacity measure assesses capacity by contrasting the minimum variable inputs for an observation with given outputs with respect to the minimal variable inputs for a translated observation producing a zero output, also net of inefficiency. Otherwise stated, while the output-oriented plant capacity measure compares output levels relative to the maximum level of outputs available, the input-oriented plant capacity measure compares variable input levels relative to the amount of variable inputs compatible with a zero output level.

The long-run plant capacity notions are now straightforward to illustrate. The long-run output-oriented plant capacity measure scales up all inputs to reach a translated point $e^{\prime \prime \prime}$ that allows maximizing the vector of outputs. The long-run input-oriented plant capacity measure now equally looks for a reduction in all inputs towards the translated point $e^{\prime \prime \prime}$ that is situated outside the isoquant $L(y)$ because it corresponds to a zero output level.

Output- and input-oriented plant capacity notions differ with respect to the concept of attainability. Johansen (1968, p. 362) already stated that the short-run output-oriented plant capacity 
notion is not attainable in that the extra variable inputs necessary to reach the maximal plant capacity output may not be available at the firm level or at the industry level. Kerstens, Sadeghi and Van de Woestyne (2018) document empirically that the amount of variable inputs needed to reach plant capacity outputs is simply implausible.

By contrast, the short-run input-oriented plant capacity notion is always attainable in that one can always reduce the amount of existing variable inputs such that one reaches an input set with zero output level. Reducing variable inputs to reach zero production levels is normally possible because of the axiom of inaction. Inaction implies that one can stop producing: but, producing a zero output need not imply that no inputs are used. Examples of zero production with positive amounts of variable inputs include maintenance activities in large industrial plants impeding production. Clearly, the same properties apply to the long-run plant capacity concepts.

We now establish a relation between the short- and long-run output-oriented plant capacity measures. Recalling that the short-run plant capacity measures leave a subvector of fixed inputs unaltered while the long-run plant capacity measures assume that all input dimensions can be varied to gauge plant capacity, the following proposition follows suit:

Proposition 1: Assuming that all conditions required for having properly defined short-and longrun output-oriented plant capacity measures (3) and (7) are satisfied, then the following relation can be established between short- and long-run output-oriented plant capacity measures (3) and (7) respectively:

$$
P C U_{o}^{L R}(x, y) \leq P C U_{o}^{S R}\left(x, x^{f}, y\right) \leq 1
$$

Proof: Since the numerator in the short-run output-oriented plant capacity measure (3) equals the numerator in the long-run output-oriented plant capacity measure (7), the result follows from $1 \leq D F_{o}\left(x^{f}, y\right) \leq D F_{o}(y)$ 
For the input-oriented short- and long-run plant capacity measures no such relation can be established. While both the numerators $\left(D F_{i}^{S R}\left(x^{f}, x^{v}, y\right) \leq D F_{i}(x, y) \leq 1\right)$ and denominators $\left(D F_{i}^{S R}\left(x^{f}, x^{v}, 0\right) \leq D F_{i}(x, 0) \leq 1\right)$ can be ranked, the ratios of both cannot be ranked.

\section{NONPARAMETRIC TECHNOLOGIES}

We choose to specify these plant capacity notions using nonparametric frontier technologies, because these primal capacity notions are difficult to estimate using traditional parametric specifications. For instance, Färe (1984) shows that a plant capacity notion cannot be obtained for certain popular parametric specifications of technology (e.g., the CES production function under certain parameter restrictions).

Therefore, plant capacity is measured relative to a nonparametric frontier technology obtained from $K$ observations $\left(x_{k}, y_{k}\right),(k=1, \ldots, K)$ imposing strong disposal of both inputs and outputs, convexity and flexible or variable returns to scale (see Hackman (2008) or Zhu (2014)):

$$
S^{V R S}=\left\{(x, y): \quad x \geq \sum_{k=1}^{K} x_{k} z_{k}, y \leq \sum_{k=1}^{K} y_{k} z_{k}, \sum_{k=1}^{K} z_{k}=1, z_{k} \geq 0\right\},
$$

where $z$ is the activity vector. ${ }^{10}$ We now turn to the computation of all plant capacity notions with respect to this variable returns to scale technology. Note that alternative assumptions on technology (e.g., constant returns to scale) are ignored. ${ }^{11}$

\footnotetext{
${ }^{10}$ This technology satisfies (S.2)-(S.4) and only partially (S.1): it satisfies no free lunch, but not inaction: see also supra.

${ }^{11}$ For instance, under constant returns to scale all capacity notions except $P C U_{o}^{S R}\left(x, x^{f}, y\right)$ are not well-defined, since some of the input and output efficiency measures are not nonzero and finite.
} 


\subsection{Short-Run Plant Capacity Utilisation}

For the sake of clarity, we explicitly add the two linear programs (LPs) for computing the short-run output-oriented plant capacity measure. For an evaluated observation $\left(x_{o}, y_{o}\right)$, one can obtain the radial output measure $D F_{o}\left(x_{o}, y_{o}\right)$ as follows:

$$
\begin{aligned}
& D F_{o}\left(x_{o}, y_{o}\right)=\max _{\theta, z} \theta \\
& \text { s.t. } \quad \sum_{k=1}^{K} y_{k m} z_{k} \geq \theta y_{o m} \quad m=1, \ldots, M, \\
& \sum_{k=1}^{K} x_{k n} z_{k} \leq x_{o n} \quad n=1, \ldots, N, \\
& \sum_{k=1}^{K} z_{k}=1, \\
& \theta \geq 0, z_{k} \geq 0, \quad k=1, \ldots, K .
\end{aligned}
$$

Following Färe, Grosskopf and Valdmanis (1989: p. 128), the efficiency measure $D F_{o}^{f}\left(x_{o}^{f}, y_{o}\right)$ is computed for observation $\left(x_{o}, y_{o}\right)$ as:

$$
\begin{gathered}
D F_{o}^{f}\left(x_{o}^{f}, y_{o}\right)=\max _{\theta, z} \theta \\
\text { s.t. } \quad \sum_{k=1}^{K} y_{k m} z_{k} \geq \theta y_{o m} \quad m=1, \ldots, M, \\
\sum_{k=1}^{K} x_{k n}^{f} z_{k} \leq x_{o n}^{f} \quad n=1, \ldots, N^{f}, \\
\sum_{k=1}^{K} z_{k}=1, \\
\theta \geq 0, z_{k} \geq 0, \quad k=1, \ldots, K .
\end{gathered}
$$

Observe that there are no input constraints on the variable inputs. Note that Färe, Grosskopf and Lovell (1994: p. 262) introduce an alternative LP with a scalar for each variable input dimension. This LP and (14) are equivalent to making each variable input a decision variable. Thus, (14) can be alternatively written as: 


$$
\begin{aligned}
& D F_{o}^{f}\left(x_{o}^{f}, y_{o}\right)=\max _{\theta, z, v^{v}} \theta \\
& \text { s.t. } \quad \sum_{k=1}^{K} y_{k m} z_{k} \geq \theta y_{o m} \quad m=1, \ldots, M, \\
& \sum_{k=1}^{K} x_{k n}^{f} z_{k} \leq x_{o n}^{f} \quad n=1, \ldots, N^{f}, \\
& \sum_{k=1}^{K} x_{k n}^{v} z_{k} \leq x_{n}^{v} \quad n=1, \ldots, N^{v}, \quad N^{f}+N^{v}=N, \\
& \sum_{k=1}^{K} z_{k}=1, \\
& \theta \geq 0, x_{n}^{v} \geq 0, z_{k} \geq 0, \quad k=1, \ldots, K .
\end{aligned}
$$

To see how the projection described in footnote 3 works, one can set $x_{k}^{v}=0$ for all $k$ in (15). Consequently, the variable input constraints become $0 \leq x_{n}^{v}$ which is always satisfied: thus, these constraints can be removed to yield (14).

Turning now to the short run input-oriented plant capacity measure, one computes the radial sub-vector input measure $D F_{i}^{S R}\left(x_{o}^{f}, x_{o}^{v}, y_{o}\right)$ for an evaluated observation $\left(x_{o}, y_{o}\right)$ :

$$
\begin{aligned}
& D F_{i}^{S R}\left(x_{o}^{f}, x_{o}^{v}, y_{o}\right)=\min _{\lambda, z} \lambda \\
& \text { s.t. } \quad \sum_{k=1}^{K} y_{k m} z_{k} \geq y_{o m} \quad m=1, \ldots, M, \\
& \sum_{k=1}^{K} x_{k n}^{f} z_{k} \leq x_{o n}^{f} \quad n=1, \ldots, N^{f}, \\
& \sum_{k=1}^{K} x_{k n}^{v} z_{k} \leq \lambda x_{o n}^{v} \quad n=1, \ldots, N^{v}, \quad N^{f}+N^{v}=N, \\
& \sum_{k=1}^{K} z_{k}=1, \\
& \lambda \geq 0, z_{k} \geq 0, \quad k=1, \ldots, K .
\end{aligned}
$$

The sub-vector efficiency measure $D F_{i}^{S R}\left(x_{o}^{f}, x_{o}^{v}, 0\right)$ is obtained for observation $\left(x_{o}, y_{o}\right)$ by solving: 


$$
\begin{aligned}
& D F_{i}^{S R}\left(x_{o}^{f}, x_{o}^{v}, 0\right)=\min _{\lambda, z} \lambda \\
& \text { s.t. } \quad \sum_{k=1}^{K} y_{k m} z_{k} \geq 0 \quad m=1, \ldots, M, \\
& \sum_{k=1}^{K} x_{k n}^{f} z_{k} \leq x_{o n}^{f} \quad n=1, \ldots, N^{f}, \\
& \sum_{k=1}^{K} x_{k n}^{v} z_{k} \leq \lambda x_{o n}^{v} \quad n=1, \ldots, N^{v}, \quad N^{f}+N^{v}=N, \\
& \sum_{k=1}^{K} z_{k}=1, \quad \\
& \lambda \geq 0, z_{k} \geq 0, \quad k=1, \ldots, K .
\end{aligned}
$$

Note that the observed output levels on the right-hand side of the output constraints are set equal to zero. $^{12}$ These zero output levels are compatible with any output levels where production is initiated. If one fixes for each output dimension the level at the minimum observed over all units, then the right-hand side would be identical for each DMU and the same solution would result for the subvector input efficiency measure $D F_{i}^{S R}\left(x_{o}^{f}, x_{o}^{v}, 0\right)$. In fact, since the output constraints are redundant, this problem can be rewritten: ${ }^{13}$

$$
\begin{aligned}
D F_{i}^{S R}\left(x_{o}^{f}, x_{o}^{v}, 0\right) & =\min _{\lambda, z} \lambda \\
\text { s.t. } \quad \sum_{k=1}^{K} x_{k n}^{f} z_{k} & \leq x_{o n}^{f} \quad n=1, \ldots, N^{f}, \\
\sum_{k=1}^{K} x_{k n}^{v} z_{k} & \leq \lambda x_{o n}^{v} \quad n=1, \ldots, N^{v}, \quad N^{f}+N^{v}=N, \\
\sum_{k=1}^{K} z_{k} & =1, \\
\lambda \geq 0, z_{k} & \geq 0, \quad k=1, \ldots, K .
\end{aligned}
$$

Observe that the LPs (14) and (18) are similar in that certain constraints are suppressed: the variable input constraints in LP (14) and the output constraints in LP (18). Given the nature of the inequality constraints, this is again similar to making the variable inputs decision variables in LP

\footnotetext{
${ }^{12}$ The determination of input utilization rates for the variable inputs is straightforward in the output-oriented case (e.g., Färe, Grosskopf and Lovell (1994: § 10.3)), the determination of optimal variable inputs is equally straightforward in this input-oriented case.

${ }^{13}$ We thank John Walden for comments that lead to formulation (18).
} 
(15) and to setting the outputs equal to zero in LP (17): both approaches allow for an arbitrary scaling of inputs downwards and of outputs upwards.

\subsection{Long-Run Plant Capacity Utilisation}

To obtain the long-run plant capacity measures, just three more efficiency measures need to be computed. For the output-oriented case, $D F_{o}\left(x_{o}, y_{o}\right)$ has already been computed in (13). One just needs to compute the efficiency measure $D F_{o}\left(y_{o}\right)$ for a given observation $\left(x_{o}, y_{o}\right)$ :

$$
\begin{aligned}
& D F_{o}\left(y_{o}\right)=\max _{\theta, x, z} \theta \\
& \text { s.t. } \quad \sum_{k=1}^{K} y_{k m} z_{k} \geq \theta y_{o m} \quad m=1, \ldots, M, \\
& \sum_{k=1}^{K} x_{k n} z_{k} \leq x_{n} \quad n=1, \ldots, N, \\
& \sum_{k=1}^{K} z_{k}=1, \\
& \theta \geq 0, x_{n} \geq 0, z_{k} \geq 0, \quad k=1, \ldots, K .
\end{aligned}
$$

This is the long-run equivalent of LP (15). Thus, the input constraints in (19) are redundant, since these constraints can take any arbitrary value. Hence, by omitting these input constraints, LP (19) simplifies to

$$
\begin{aligned}
& D F_{o}\left(y_{o}\right)=\max _{\theta, z} \theta \\
\text { s.t. } \quad \sum_{k=1}^{K} y_{k m} z_{k} & \geq \theta y_{o m} \quad m=1, \ldots, M, \\
\sum_{k=1}^{K} z_{k} & =1, \\
\theta \geq 0, z_{k} & \geq 0, \quad k=1, \ldots, K .
\end{aligned}
$$

This is the long-run equivalent of LP (14). To see how the projection described in footnote 4 works, one can set $x_{k}=0$ for all $k$ in (19). Consequently, the input constraints become $0 \leq x_{n}$ which is always satisfied: thus, these constraints can be removed to yield (20).

Finally, for the input-oriented case, the efficiency measure $D F_{i}\left(x_{o}, y_{o}\right)$ is calculated for a given observation $\left(x_{o}, y_{o}\right)$ as follows: 


$$
\begin{gathered}
D F_{i}\left(x_{o}, y_{o}\right)=\min _{\lambda, z} \lambda \\
\text { s.t. } \quad \sum_{k=1}^{K} y_{k m} z_{k} \geq y_{o m} \quad m=1, \ldots, M, \\
\sum_{k=1}^{K} x_{k n} z_{k} \leq \lambda x_{o n} \quad n=1, \ldots, N, \\
\sum_{k=1}^{K} z_{k}=1, \\
\lambda \geq 0, z_{k} \geq 0, \quad k=1, \ldots, K .
\end{gathered}
$$

Last but not least, the efficiency measure $D F_{i}\left(x_{0}, 0\right)$ is obtained for observation $\left(x_{o}, y_{o}\right)$ by solving:

$$
\begin{aligned}
D F_{i}\left(x_{o}, 0\right) & =\min _{\lambda, z} \lambda \\
\text { s.t. } \quad \sum_{k=1}^{K} y_{k m} z_{k} & \geq 0 \quad m=1, \ldots, M, \\
\sum_{k=1}^{K} x_{k n} z_{k} & \leq \lambda x_{o n} \quad n=1, \ldots, N, \\
\sum_{k=1}^{K} z_{k} & =1, \\
\lambda \geq 0, z_{k} & \geq 0, \quad k=1, \ldots, K .
\end{aligned}
$$

Note again that the observed output levels on the right-hand side of the output constraints are constrained to equal zero. Again, these zero output levels are compatible with any output levels where production is initiated. If each output dimension is fixed at the level of the minimum observed over all units, then the right-hand side would be identical for each DMU and the same solution would result for the input efficiency measure $D F_{i}\left(x_{o}, 0\right)$. Again, since the output constraints are redundant, this problem simplifies as follows:

$$
\begin{aligned}
D F_{i}\left(x_{o}, 0\right) & =\min _{\lambda, z} \lambda \\
\text { s.t. } \quad \sum_{\mathrm{k}=1}^{K} x_{k n} z_{k} & \leq \lambda x_{o n} \quad n=1, \ldots, N, \\
\sum_{k=1}^{K} z_{k} & =1, \\
\lambda \geq 0, z_{k} & \geq 0, \quad k=1, \ldots, K .
\end{aligned}
$$


Observe that the LPs (20) and (23) are similar in that some constraints are eliminated: all input constraints in LP (20) and again all output constraints in LP (23). Given the nature of the inequality constraints, we again make all inputs decision variables in LP (19) and we set all outputs equal to zero in LP (22). This makes an arbitrary scaling of the inputs downwards and of the outputs upwards possible.

\subsection{Relation with Lovell and Pastor (1999)}

Here we establish a link between some of our short- and long-run plant capacity models and the models without inputs or without outputs proposed in Lovell and Pastor (1999). Further refinements of these Lovell and Pastor (1999) models are found in Amirteimoori et al. (2013), Liu et al. (2001), Toloo and Tavana (2017), and Yang et al. (2014).

Remark that LP (20) is formally identical to the output-oriented efficiency measure computed relative to a convex variable returns to scale technology without inputs proposed by Lovell and Pastor (1999). An early empirical application is Lovell and Pastor (1997) who have applied such a model to a target setting procedure established by a large Spanish savings bank. More recent examples include Horta, Camanho and. Moreira da Costa (2012) as well as Horta and Camanho (2014). We are inclined to think that in a clear production setting where inputs can be specified (but are not for whatever reason), such a model can be interpreted as an estimate of the long run output-oriented plant capacity.

Clearly, such model without inputs is also often used when evaluating so-called synthetic indicators. When efficiency measures are used to summarise or aggregate the information provided by several variables for which improvements are desirable (more is better, just like in the case of outputs) but the link to a real production process where physical inputs are transformed into physical outputs is at best indirect, then we can call this a synthetic indicator. Cherchye et al. (2007) provide an introduction and motivation to this literature (calling it a 'benefit of the doubt' approach). We provide some examples to clarify what we mean. First, there is a literature assessing the efficiency 
of combined accounting ratios (e.g., see Cai and Wu (2001) or Halkos and Salamouris (2004)). For instance, Halkos and Salamouris (2004) summarise the performance of Greek banks by combining six accounting ratios: return difference of interest bearing assets (RDIBA), return on equity (ROE), return on total assets (ROA), profit/loss per employee (P/L), net interest margin (NIM), and an efficiency ratio (EFF) defined as operational expenses divided by gross operating profit/loss. However, since three of the outputs (ROE, ROA, and P/L) have a common numerator (i.e, profit/loss before tax), there is clearly a problem of double counting which prevents interpreting this as a strict production process. Second, there is a literature evaluating economic and social policies using synthetic indicators (the Human Development Index is a well-known example). For instance, in a similar vein Lefèbvre, Coelli and Pestieau (2010) evaluate welfare states using a synthetic indicator of social protection by aggregating the following variables: at-risk-of-poverty rate, inequality of income distribution, longterm unemployment, early school leavers, and life expectancy. Again, it is hard to maintain that there is a strict production process. In conclusion, when we leave a clear production setting and inputs cannot be specified because we simply aggregate a series of outputs in a synthetic indicator, then the fact that we use the same formal model (20) does not imply that it makes sense to interpret the outcome as a biased long-run output-oriented plant capacity measure.

Further remark that the LPs (18) and (23) are related to the input-oriented efficiency measure computed relative to a convex variable returns to scale technology without outputs proposed by Lovell and Pastor (1999). Again, in a clear production setting where outputs can be specified (but are not for whatever reason), we are inclined to think that such a model can be interpreted as an estimate of the short-run (18) or long-run (23) input-oriented plant capacity. Clearly, when we leave a clear production setting and outputs can simply not be specified (e.g., in case of synthetic indicators where we summarise or aggregate in this case the information provided by several variables for which reductions are desirable (less is better, just like in the case of inputs)), then of course the above interpretation is not valid. We are unaware of any other economic context in which these specific variable returns to scale models without outputs have ever been used. 


\section{NUMERICAL ILLUSTRATION}

We illustrate the ease of implementing some of the new plant capacity definitions introduced in this contribution by using a small set of artificial data. Table 1 contains 16 fictitious observations with two inputs generating a single output: one input is variable, the other one is fixed. A three-dimensional representation of the technology resulting from these 16 fictitious observations is provided by Figures 2 and 3.

Table 1: Numerical Example Containing 16 observations

\begin{tabular}{rrrr}
\hline \multicolumn{1}{c}{$N r$} & \multicolumn{1}{c}{$x^{v}$} & \multicolumn{1}{c}{$x^{f}$} \\
\hline 1 & 1.0 & 7.0 & 3.0 \\
2 & 2.0 & 5.0 & 3.0 \\
3 & 4.5 & 2.0 & 3.0 \\
4 & 6.0 & 1.0 & 3.0 \\
5 & 7.5 & 4.0 & 3.0 \\
6 & 2.0 & 9.5 & 4.0 \\
7 & 10.0 & 2.0 & 4.0 \\
8 & 5.5 & 6.0 & 4.0 \\
9 & 6.0 & 3.5 & 4.0 \\
10 & 6.5 & 6.5 & 5.0 \\
11 & 5.5 & 8.5 & 5.0 \\
12 & 9.0 & 5.0 & 5.0 \\
13 & 10.0 & 4.5 & 5.0 \\
14 & 7.0 & 10.0 & 6.0 \\
15 & 8.0 & 8.0 & 6.0 \\
16 & 10.0 & 6.0 & 6.0 \\
\hline
\end{tabular}

Figure 2 illustrates the relation between the set $S$ and its projections $S^{f}$ and $P$ (mentioned in Section 2) in case of a variable returns to scale technology obtained from the 16 available observations (grey coloured dots). Technology $S$ consists of two inputs (the variable input $x^{v}$ and the fixed input $x^{f}$ ) and one output $(y)$ and is visible by means of its convex boundary. Setting all variable inputs equal to zero yields the short run technology $S^{f}$ visualised by the red piecewise linear convex region in the fixed input output plane. The projections of the original 16 observations are visible by means of red coloured boxes. Finally, setting all inputs equal to zero results in the output 
set $P$ visible as the green interval on the $y$-axis. The original 16 observations are now projected onto the corresponding points indicated by green diagonal crosses.

Having explained the relations between the technology $\mathrm{S}$ and its projections, we now turn to an illustration of all plant capacity measures. The short-run and long-run output-oriented plant capacity measures are illustrated using Figure 2. By contrast, both input-oriented plant capacity measures are elucidated using Figure 3.

First, Figure 2 illustrates the components of the output-oriented capacity measures defined by (3) and (7). Consider observation $a$ with inputs $x_{v}=7.5, x_{f}=5.5$, and output $y=3.5$. Then, $D F_{o}(x, y)=\frac{\left|a_{1} b\right|}{\left|a_{1} a\right|}=1.4505$ and $D F_{o}^{f}\left(x^{f}, y\right)=\frac{\left|a_{3} c_{2}\right|}{\left|a_{3} a_{2}\right|}=\frac{\left|c_{1} c\right|}{\left|a_{1} a\right|}=1.6429$. Using (3), we conclude that $P C U_{o}^{S R}\left(x, x^{f}, y\right)=\frac{1.4505}{1.6429}=0.8829$. Since $D F_{o}(y)=\frac{\left|d_{1} d\right|}{\left|a_{1} a\right|}=1.7143$, equation (7) yields $P C U_{o}^{L R}(x, y)=\frac{1.4505}{1.7143}=0.8462$. This example satisfies Proposition 1.

Second, Figure 3 illustrates the components of the input-oriented capacity measures defined by (5) and (9). To serve this illustration, two sections are added to Figure 3: the section by the plane $\alpha$ parallel to the variable input axis (which is also visible in Figure 2) represents the short-run plant capacity measure; the section by the plane $\beta$ going through the origin intends to illustrate the longrun plant capacity measure. These two sections have been projected in two dimensions in Figure 4: the horizontal axis represents the variable input, the vertical axis denotes the output. The section representing the short-run plant capacity measure is denoted by the black polyline; the section depicting the long-run plant capacity measure is denoted by the red dashed polyline. 
Figure 2: Technology $S$ and its Projections $S^{f}$ and $P$ : Output-Oriented Plant Capacity

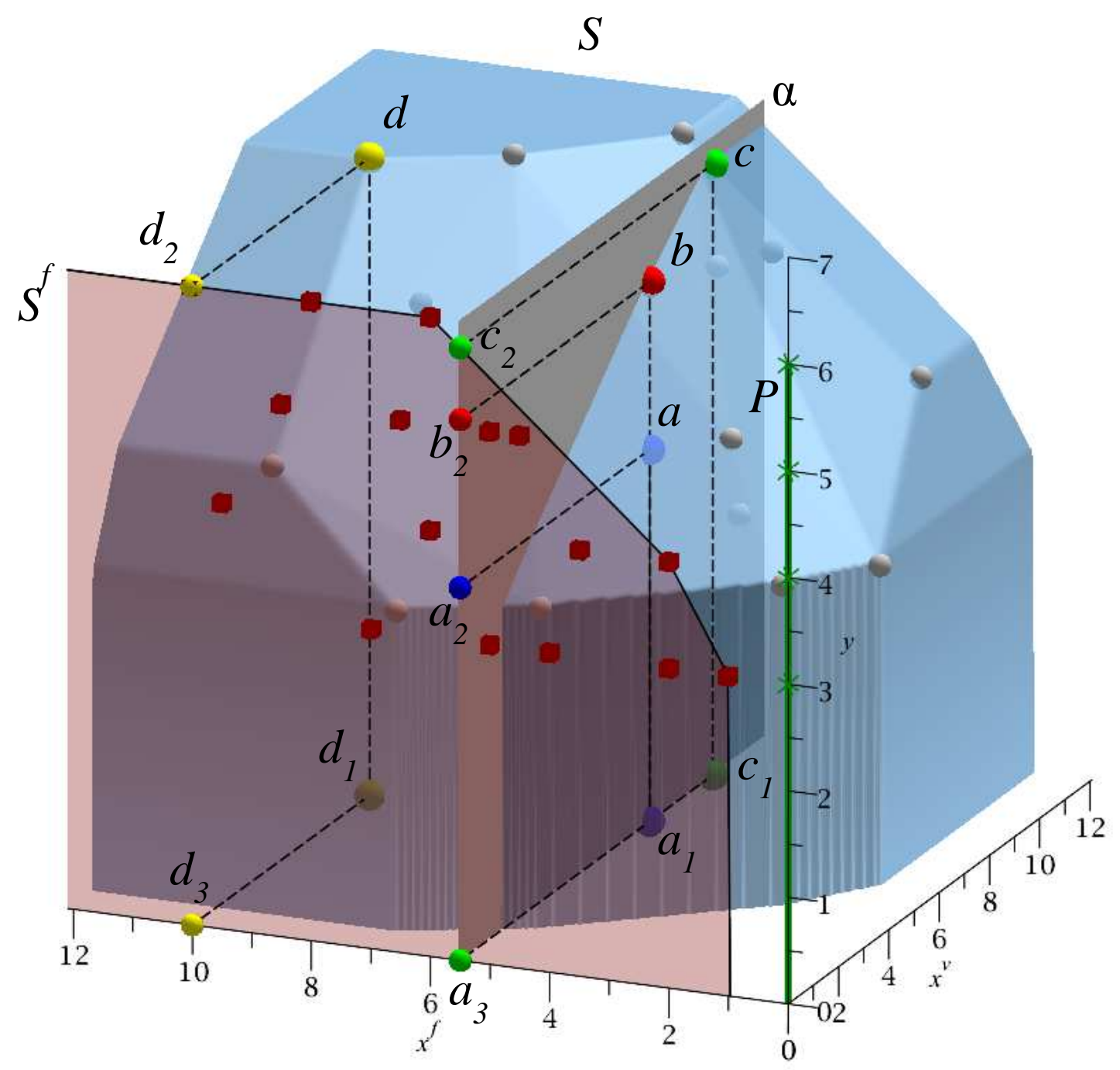


Figure 3: Technology $S$ : Input-Oriented Plant Capacity

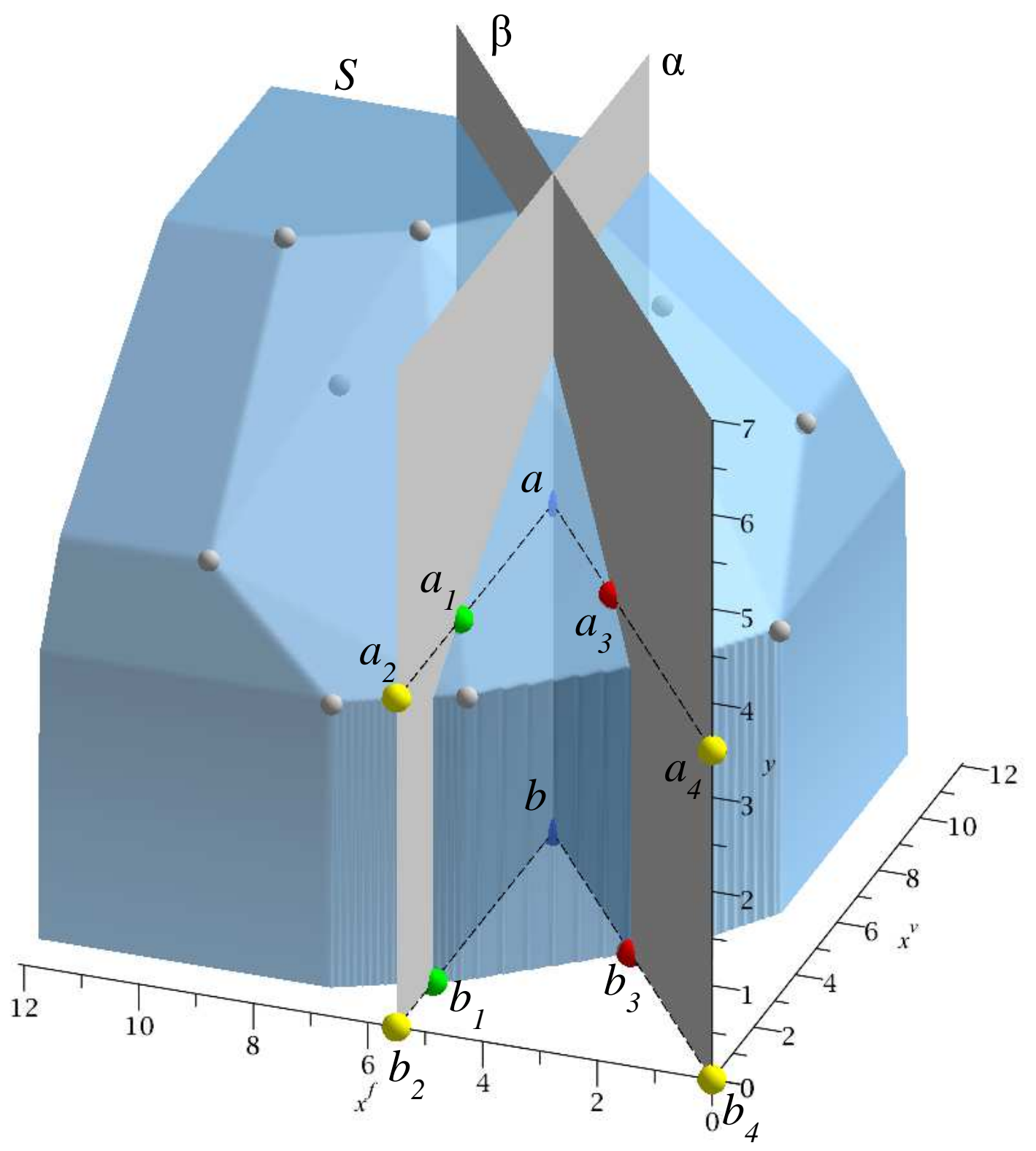


Again, consider observation $a$ with inputs $x_{v}=7.5, x_{f}=5.5$, and output $y=3.5$. This observation is visible both in Figures 3 and 4. Then, $D F_{i}^{S R}\left(x^{f}, x^{v}, y\right)=\frac{\left|a_{2} a_{1}\right|}{\left|a_{2} a\right|}=0.4000$ while $D F_{i}^{S R}\left(x^{f}, x^{v}, 0\right)=\frac{\left|b_{2} b_{1}\right|}{\left|b_{2} b\right|}=0.2333$. Hence, $P C U_{i}^{S R}\left(x, x^{f}, y\right)=\frac{0.4000}{0.2333}=1.7143$ using equation (5). Since $D F_{i}(x, y)=\frac{\left|a_{4} a_{3}\right|}{\left|a_{4} a\right|}=0.6241$ and $D F_{i}(x, 0)=\frac{\left|b_{4} b_{3}\right|}{\left|b_{4} b\right|}=0.5103$, equation (9) returns $P C U_{i}^{L R}(x, y)=\frac{0.6241}{0.5103}=1.2230$

Figure 4: Short Run Technology $S^{f}$ Constructed from Numerical Example

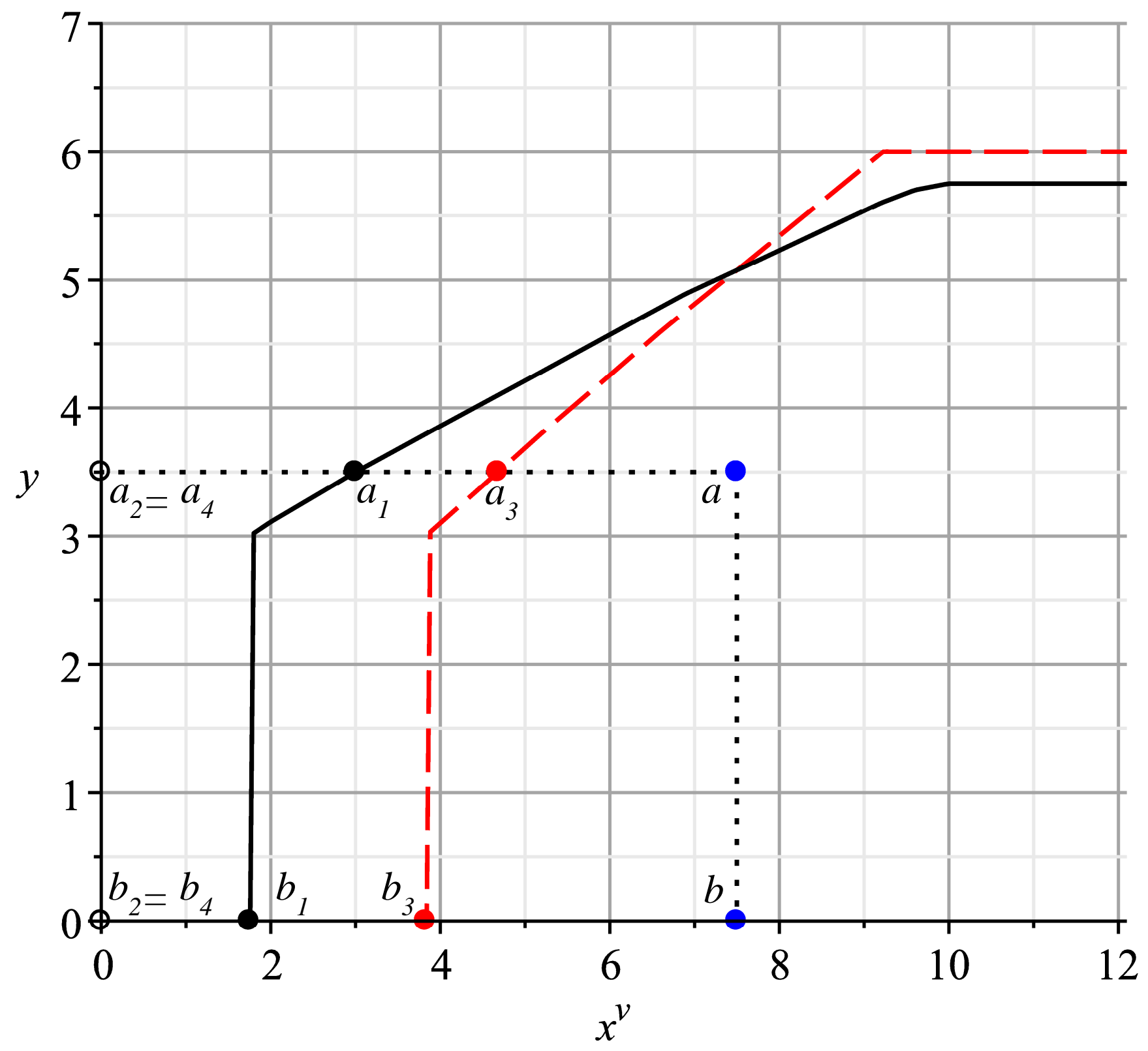

-- Long run section - Short run section 
Similar computations as those illustrated above can be executed on all observations provided in Table 1. The resulting plant capacity measures and its components are reported in Tables 2 (output-oriented) and 3 (input-oriented).

Table 2: Output-oriented Short- and Long-run Efficiency Results and Plant Capacity Utilisation

\begin{tabular}{rccccc}
\hline$N r$ & $D F_{o}(x, y)$ & $D F_{o}^{f}\left(x^{f}, y\right)$ & $D F_{o}(y)$ & $P C U_{o}^{L R}()$. & $P C U_{o}^{S R}()$. \\
\hline 1 & 1.0000 & 2.0000 & 2.0000 & 0.5000 & 0.5000 \\
2 & 1.0000 & 1.8333 & 2.0000 & 0.5000 & 0.5455 \\
3 & 1.0000 & 1.3333 & 2.0000 & 0.5000 & 0.7500 \\
4 & 1.0000 & 1.0000 & 2.0000 & 0.5000 & 1.0000 \\
5 & 1.5250 & 1.6667 & 2.0000 & 0.7625 & 0.9150 \\
6 & 1.0000 & 1.5000 & 1.5000 & 0.6667 & 0.6667 \\
7 & 1.0000 & 1.0000 & 1.5000 & 0.6667 & 1.0000 \\
8 & 1.1339 & 1.5000 & 1.5000 & 0.7560 & 0.7560 \\
9 & 1.0000 & 1.1875 & 1.5000 & 0.6667 & 0.8421 \\
10 & 1.0071 & 1.2000 & 1.2000 & 0.8393 & 0.8393 \\
11 & 1.0278 & 1.2000 & 1.2000 & 0.8565 & 0.8565 \\
12 & 1.0700 & 1.1000 & 1.2000 & 0.8917 & 0.9727 \\
13 & 1.0500 & 1.0500 & 1.2000 & 0.8750 & 1.0000 \\
14 & 1.0000 & 1.0000 & 1.0000 & 1.0000 & 1.0000 \\
15 & 1.0000 & 1.0000 & 1.0000 & 1.0000 & 1.0000 \\
16 & 1.0000 & 1.0000 & 1.0000 & 1.0000 & 1.0000 \\
\hline
\end{tabular}

Table 3: Input-oriented Short- and Long-run Efficiency Results and Plant Capacity Utilisation

\begin{tabular}{rcccccc}
\hline$N r$ & $D F_{i}(x, y)$ & $D F_{i}(x, 0)$ & $D F_{i}^{S R}\left(x^{f}, x^{v}, y\right)$ & $D F_{i}^{S R}\left(x^{f}, x^{v}, 0\right)$ & $P C U_{i}^{L R}()$. & $P C U_{i}^{S R}()$. \\
\hline 1 & 1.0000 & 1.0000 & 1.0000 & 1.0000 & 1.0000 & 1.0000 \\
2 & 1.0000 & 1.0000 & 1.0000 & 1.0000 & 1.0000 & 1.0000 \\
3 & 1.0000 & 1.0000 & 1.0000 & 1.0000 & 1.0000 & 1.0000 \\
4 & 1.0000 & 1.0000 & 1.0000 & 1.0000 & 1.0000 & 1.0000 \\
5 & 0.5692 & 0.5692 & 0.3778 & 0.3778 & 1.0000 & 1.0000 \\
6 & 1.0000 & 0.6667 & 1.0000 & 0.5000 & 1.5000 & 2.0000 \\
7 & 1.0000 & 0.5769 & 1.0000 & 0.4500 & 1.7333 & 2.2222 \\
8 & 0.8544 & 0.5873 & 0.7273 & 0.2727 & 1.4547 & 2.6667 \\
9 & 1.0000 & 0.6916 & 1.0000 & 0.5417 & 1.4459 & 1.8462 \\
10 & 0.9915 & 0.5175 & 0.9846 & 0.1923 & 1.9159 & 5.1200 \\
11 & 0.9655 & 0.4901 & 0.9351 & 0.1818 & 1.9702 & 5.1429 \\
12 & 0.9176 & 0.4684 & 0.8611 & 0.2222 & 1.9593 & 3.8750 \\
13 & 0.9286 & 0.4485 & 0.8400 & 0.2417 & 2.0705 & 3.4759 \\
14 & 1.0000 & 0.4022 & 1.0000 & 0.1429 & 2.4865 & 7.0000 \\
15 & 1.0000 & 0.4205 & 1.0000 & 0.1250 & 2.3784 & 8.0000 \\
16 & 1.0000 & 0.4111 & 1.0000 & 0.1500 & 2.4324 & 6.6667 \\
\hline
\end{tabular}




\section{EMPIRICAL APPLICATION}

We now illustrate the newly introduced plant capacity measures on a selection of observations drawn from the data set used in Atkinson and Halabí (2005) and Atkinson and Dorfman (2009) concerning Chilean hydroelectric power plants. From the initial data set containing monthly data related to 21 power plants in the period 1986-1997, all records for the year 1989 only are selected. This results in 252 observations: 84 of these have missing data and are thus not considered. Hence, technology in this application contains 168 observations with electricity production as output and capital, water and labour as inputs.

For the short-run capacity measures, capital is considered a fixed input while water and labour are considered variable inputs. Descriptive statistics of inputs and output are reported in the first part of Table 4. Observe from the minimum values that there are observations with zero inputs and zero outputs. In the second part of Table 4, three individual observations are presented, one of which having zero output and one zero input (i.e., water). While a zero variable input is no problem given that there is another non-zero variable input, a zero output in the single output case violates the conditions on the data initially imposed. Since these hydro-power plants are run-of-river type, having a zero output is definitely technologically possible during maintenance. Hence, the existence of solutions for the efficiency measures is no longer guaranteed.

Table 4: Descriptive Statistics for the Year 1989 and Selection of Three Individual Observations

\begin{tabular}{lrrrr}
\hline & $\begin{array}{l}\text { Production (kWh) } \\
\text { (output) }\end{array}$ & $\begin{array}{l}\text { Capital } \\
\text { (fixed input) }\end{array}$ & $\begin{array}{l}\text { Water } \\
\text { (variable input) }\end{array}$ & $\begin{array}{l}\text { Labour } \\
\text { (variable input) }\end{array}$ \\
\hline Average & 61.63 & 667084.10 & 158.50 & 51.80 \\
St. Dev. & 76.88 & 747531.11 & 150.21 & 36.85 \\
Min & 0.00 & 32779.66 & 0.00 & 4.00 \\
Max & 353.70 & 3732850.00 & 677.30 & 142.00 \\
\hline Plant 2 in March & 0.00 & 77863.93 & 0.00 & 79.00 \\
Plant 3 in January & 30.00 & 105114.70 & 72.00 & 33.00 \\
Plant 11 in May & 242.50 & 1742383.00 & 205.65 & 89.87 \\
\hline
\end{tabular}


For all 168 observations, efficiencies composing both the short- and long-run efficiency measures are computed. Summarising descriptive statistics of these results for the output oriented measures can be found in the first part of Table 5. Notice a total of 10 infeasibilities corresponding with those observations having zero outputs. For these observations the corresponding LPs are unbounded leading to these infeasibilities. The second part of Table 5 reports the resulting values for the three selected observations. Since power plant 2 has zero output in March, all output PCUmeasures are infeasible. Consequently, the output PCU-measures are not well-defined in the case of zero outputs. For power plant 3 in January, the long- and short-run PCU-measures are 0.086 and 0.826 respectively, while for power plant 11 in May a long-run PCU of 0.761 and a short-run PCU of 0.920 are obtained. Considering the latter plant, these values can be interpreted as follows. In the long-run scenario, the output oriented efficiency measure of power plant 11 in May equals $76.1 \%$ of the maximal possible output oriented efficiency obtained by ignoring all inputs. Roughly speaking, one could say that power plant 11 produces at a level of $76.1 \%$ of its maximal output capacity. When considering the short-run scenario, this capacity increases to $92 \%$ of the maximal output capacity.

Table 5: Output-oriented Short- and Long-run Efficiency Results and Plant Capacity Utilisation

\begin{tabular}{lrrrrr}
\hline & $D F_{o}(x, y)$ & $D F_{o}^{f}\left(x^{f}, y\right)$ & $D F_{o}(y)$ & $P C U_{o}^{L R}()$. & $P C U_{o}^{S R}()$. \\
\hline Average & 1.720 & 3.017 & 16.651 & 0.277 & 0.742 \\
St. Dev. & 1.043 & 5.047 & 16.850 & 0.283 & 0.230 \\
Min & 1.000 & 1.000 & 1.000 & 0.013 & 0.094 \\
Max & 6.974 & 59.357 & 86.268 & 1.000 & 1.000 \\
\# infeasible & 10 & 10 & 10 & 10 & 10 \\
\hline Plant 2 in March & inf & inf & inf & inf & inf \\
Plant 3 in January & 1.009 & 1.222 & 11.790 & 0.086 & 0.826 \\
Plant 11 in May & 1.110 & 1.207 & 1.459 & 0.761 & 0.920 \\
\hline
\end{tabular}

For the input oriented PCU-measures, the summary descriptive statistics are available in the first part of Table 6. Contrary to the output oriented case, no infeasibilities occur for observations having zero outputs. The second part of Table 6 again reports the results for the three selected 
power plants. Power plant 2 has zero output in March. Consequently, the efficiencies in the numerator and denominator of PCU-measures (5) and (9) coincide, leading to a value of 1 . Power plant 11 now has coinciding long- and short-run PCU-measures while this is not the case for power plant 3 in January. The long-run PCU-measure of 3.174 represents the factor by which the minimum possible input oriented efficiency (i.e., obtained by allowing zero outputs) must be multiplied to obtain the input efficiency of power plant 3 in January. Put differently, one could say that power plant 3 uses in January in optimal circumstances (i.e., when inputs would be reduced to the minimum possible level accommodating the given output) $317.4 \%$ of the minimum possible inputs provided that no output is required. In the short-run scenario, this value increases to $628.7 \%$.

Table 6: Input-oriented Short- and Long-run Efficiency Results and Plant Capacity Utilisation

\begin{tabular}{lrrrrrr}
\hline & $D F_{i}(x, y)$ & $D F_{i}(x, 0)$ & $D F_{i}^{S R}\left(x^{f}, x^{v}, y\right)$ & $D F_{i}^{S R}\left(x^{f}, x^{v}, 0\right)$ & $P C U_{i}^{L R}()$. & $P C U_{i}^{S R}()$. \\
\hline Average & 0.744 & 0.403 & 0.646 & 0.315 & 5.121 & 5.143 \\
St. Dev. & 0.251 & 0.360 & 0.313 & 0.353 & 6.237 & 5.818 \\
Min & 0.172 & 0.028 & 0.145 & 0.028 & 1.000 & 1.000 \\
Max & 1.000 & 1.000 & 1.000 & 1.000 & 35.000 & 35.000 \\
\# infeasible & 0 & 0 & 0 & 0 & 0 & 0 \\
\hline Plant 2 in March & 1.000 & 1.000 & 1.000 & 1.000 & 1.000 & 1.000 \\
Plant 3 in January & 0.990 & 0.312 & 0.979 & 0.156 & 3.174 & 6.287 \\
Plant 11 in May & 0.897 & 0.055 & 0.897 & 0.055 & 16.273 & 16.273 \\
\hline
\end{tabular}

\section{CONCLUSIONS}

This contribution introduces new output- and input-oriented plant capacity measures taking a long-run perspective complementing the existing short-run output- and input-oriented plant capacity measures. While the short-run output- and input-oriented plant capacity measures leave a subvector of fixed inputs unaltered, the new long-run plant capacity measures allow for changes in all input dimensions to determine either a maximal plant capacity output in the output-oriented case or a minimal input combination at which non-zero production starts in the input-oriented case.

Also a relation between these short- and long-run plant capacity measures has been established. For a standard nonparametric frontier technology with variable returns to scale, all linear 
programs (including some variations) are discussed computing the efficiency measures defining these plant capacity concepts. We also develop a relation with frontier models without inputs and without outputs: these long-run plant capacity measures turn out to offer a perfect production economic justification for the use of these existing frontier models earlier proposed by Lovell and Pastor (1999). A numerical example has served to clarify the geometric intuition behind these new plant capacity measures and Section 5 illustrates these relations between short-run and long-run plant capacity concepts. Section 6 has reported a short empirical application.

In a companion paper, Kerstens, Sadeghi and Van de Woestyne (2017) compare both shortand long-run input- and output-oriented plant capacity notions to the rather popular cost-based notions of capacity utilisation. It rather clearly turns out that the input-oriented plant capacity notions rank correlate better than the output-oriented plant capacity notions with these various costbased notions of capacity utilisation. Obviously, it is desirable that more studies try to corroborate these preliminary findings.

Though the existing short-run plant capacity measures have enjoyed some popularity among applied economists, it is fair to say that these concepts have mainly been employed in a specialised efficiency literature. We hope these new long-run plant capacity definitions can contribute to enlarge the empirical toolbox available for practitioners in production economics at large.

\section{REFERENCES}

Amirteimoori, A., B. Daneshian, S. Kordrostami, K. Shahroodi (2013) Production Planning in Data Envelopment Analysis Without Explicit Inputs, RAIRO-Operations Research, 47(3), 273-284.

Atkinson, S. E., J. H. Dorfman (2009) Feasible Estimation of Firm-Specific Allocative Inefficiency Through Bayesian Numerical Methods, Journal of Applied Econometrics, 24(1), 675-697. 
Atkinson, S. E., C.E. Halabí (2005) Economic Efficiency and Productivity Growth in the PostPrivatization Chilean Hydroelectric Industry, Journal of Productivity Analysis, 23(1), 245-273.

Cai, Y., W. Wu (2001) Synthetic Financial Evaluation by a Method of Combining DEA with AHP, International Transactions in Operational Research, 8(5), 603-609.

Cesaroni, G., K. Kerstens, I. Van de Woestyne (2017) A New Input-Oriented Plant Capacity Notion: Definition and Empirical Comparison, Pacific Economic Review, 22(4), 720-739.

Cherchye, L., W. Moesen, N. Rogge, T. Van Puyenbroeck (2007) An Introduction to 'Benefit of the Doubt' Composite Indicators, Social Indicators Research, 82(1), 111-145.

De Borger, B., K. Kerstens (2000) The Malmquist Productivity Index and Plant Capacity Utilization, Scandinavian Journal of Economics, 102(2), 303-310.

De Borger, B., K. Kerstens, D. Prior, I. Van de Woestyne (2012) Static Efficiency Decompositions and Capacity Utilisation: Integrating Technical and Economic Capacity Notions, Applied Economics, 44(31), 4125-4141.

Färe, R. (1984) The Existence of Plant Capacity, International Economic Review, 25(1), 209-213.

Färe, R., S. Grosskopf, J. Kirkley (2000) Multi-Output Capacity Measures and Their Relevance for Productivity, Bulletin of Economic Research, 52(2), 101-112.

Färe, R., S. Grosskopf, E. Kokkelenberg (1989) Measuring Plant Capacity, Utilization and Technical Change: A Nonparametric Approach, International Economic Review, 30(3), 655-666.

Färe, R., S. Grosskopf, V. Valdmanis (1989) Capacity, Competition and Efficiency in Hospitals: A Nonparametric Approach, Journal of Productivity Analysis, 1(2), 123-138.

Färe, R., S. Grosskopf, C.A.K. Lovell (1994) Production Frontiers, Cambridge, Cambridge University Press.

Felthoven, R.G. (2002) Effects of the American Fisheries Act on Capacity, Utilization and Technical Efficiency, Marine Resource Economics, 17(3), 181-205. 
Grifell-Tatjé, E., C.A.K. Lovell (2014) Productivity, Price Recovery, Capacity Constraints and their Financial Consequences, Journal of Productivity Analysis, 41(1), 3-17.

Guyader, O., F. Daurès (2005) Capacity and Scale Inefficiency: Application of Data Envelopment Analysis in the Case of the French Seaweed Fleet, Marine Resource Economics, 20(4), 347-365.

Hackman, S.T. (2008) Production Economics: Integrating the Microeconomic and Engineering Perspectives, Berlin, Springer.

Halkos, G.E., D.S. Salamouris (2004) Efficiency Measurement of the Greek Commercial Banks with the Use of Financial Ratios: A Data Envelopment Analysis Approach, Management Accounting Research, 15(2), 201-224.

Hickman, B.G. (1964) On a New Method for Capacity Estimation, Journal of the American Statistical Association, 59(306), 529-549.

Horta, I.M., A.S. Camanho (2014) Competitive Positioning and Performance Assessment in the Construction Industry, Expert Systems with Applications, 41(4), 974-983.

Horta, I.M., A.S. Camanho, J. Moreira da Costa (2012) Performance Assessment of Construction Companies: A Study of Factors Promoting Financial Soundness and Innovation in the Industry, International Journal of Production Economics, 137(1), 84-93.

Johansen, L. (1968) Production Functions and the Concept of Capacity, Namur, Recherches Récentes sur la Fonction de Production (Collection "Economie Mathématique et Econometrie", n²) [reprinted in F.R. Førsund (ed.) (1987) Collected Works of Leif Johansen, Volume 1, Amsterdam, North Holland, 359-382].

Karagiannis, R. (2015) A System-of-Equations Two-Stage DEA Approach for Explaining Capacity Utilization and Technical Efficiency, Annals of Operations Research, 227(1), 25-43.

Kerr, C.A., J.C. Glass, G.M. McCallion, D.G. McKillop (1999) Best-Practice Measures of Resource Utilization for Hospitals: A Useful Complement in Performance Assessment, Public Administration, 77(3) 639-650. 
Kerstens, K., J. Sadeghi, I. Van de Woestyne (2017) Convex and Nonconvex Input-Oriented Technical and Economic Capacity Measures: An Empirical Comparison, Lille, IESEG School of Management (Working paper 2017-EQM-08), 24 pp.

Kerstens, K., J. Sadeghi, I Van de Woestyne (2018) Plant Capacity and Attainability: Exploration and Remedies, Operations Research, forthcoming.

Kirkley, J.E., D.E. Squires, M.F. Alam, H.O. Ishak (2003) Excess Capacity and Asymmetric Information in Developing Country Fisheries: The Malaysian Purse Seine Fishery, American Journal of Agricultural Economics, 85(3), 647-662.

Klein, L.R. (1960) Some Theoretical Issues in the Measurement of Capacity, Econometrica, 28(2), 272-286.

Lefèbvre, M., T. Coelli, P. Pestieau (2010) On the Convergence of Social Protection Performance in the European Union, CESifo Economic Studies, 56(2), 300-322.

Liu, W.B., D.Q. Zhang, W. Meng, X.X. Li, F. Xu (2011) A Study of DEA Models Without Explicit Inputs, Omega, 39(5), 472-480.

Lovell, C.A.K., J.T. Pastor (1997) Target Setting: An Application to a Bank Branch Network, European Journal of Operational Research, 98(2), 290-299.

Lovell, C.A.K., J.T. Pastor (1999) Radial DEA Models Without Inputs or Without Outputs, European Journal of Operational Research, 118(1), 46-51.

Magnussen, J., L. Rivers Mobley (1999) The Impact of Market Environment on Excess Capacity and the Cost of an Empty Hospital Bed, International Journal of the Economics of Business, 6(3), 383-398.

Nelson, R. (1989) On the Measurement of Capacity Utilization, Journal of Industrial Economics, 37(3), 273-286.

Reid, C., D. Squires, Y. Jeon, L. Rodwell, R. Clarke (2003) An Analysis of Fishing Capacity in the Western and Central Pacific Ocean Tuna Fishery and Management Implications, Marine Policy, 27(6), 449-469. 
Segerson, K., D. Squires (1990) On the Measurement of Economic Capacity Utilization for MultiProduct Industries, Journal of Econometrics, 44(3), 347-361.

Toloo, M., M. Tavana (2017) A Novel Method for Selecting a Single Efficient Unit in Data Envelopment Analysis Without Explicit Inputs/Outputs, Annals of Operations Research, 253(1), 657-681.

Valdmanis, V., P. Bernet, J. Moises (2010) Hospital Capacity, Capability, and Emergency Preparedness, European Journal of Operational Research, 207(3), 1628-1634.

Valdmanis, V., A. DeNicola, P. Bernet (2015) Public Health Capacity in the Provision of Health Care Services, Health Care Management Science, 18(4), 475-482.

Walden, J.B., D. Tomberlin (2010) Estimating Fishing Vessel Capacity: A Comparison of Nonparametric Frontier Approaches, Marine Resource Economics, 25(1), 23-36.

Yagi, M., S. Managi (2011) Catch Limits, Capacity Utilization and Cost Reduction in Japanese Fishery Management, Agricultural Economics, 42(5), 577-592.

Yang, G., W. Shen, D. Zhang, W. Liu (2014) Extended Utility and DEA Models Without Explicit Input, Journal of the Operational Research Society, 65(8), 1212-1220.

Yu, M.-M. (2007) The Capacity Productivity Change and The Variable Input Productivity Change: A New Decomposition of the Malmquist Productivity Index, Applied Mathematics and Computation, 185(1), 375-381.

Zhu, J. (2014) Quantitative Models for Performance Evaluation and Benchmarking: Data Envelopment Analysis with Spreadsheets, $3^{\text {rd }}$ Edition, Berlin, Springer. 